\title{
SOSIALISASI URBAN FARMING MELALUI BUDIDAYA TANAMAN SAYURAN SECARA VERTIKULTUR DAN HIDROPONIK DI KELURAHAN KALIJAGA, KECAMATAN HARJAMUKTI, KOTA CIREBON
}

\section{URBAN FARMING SOCIALIZATION THROUGH VERTICULTURE AND HYDROPONIC VEGETABLES PLANTATION IN KALIJAGA VILLAGE, HARJAMUKTI DISTRICT, CIREBON CITY}

\author{
Wachdijono ${ }^{1 a}$, Siti Wahyuni' ${ }^{1}$ Umi Trisnaningsih'1 \\ ${ }^{1}$ Fakultas Pertanian, Prodi Agribisnis Universitas Swadaya Gunung Jati, Jl. Pemuda No. 32 \\ Cirebon \\ aKorespondensi:Wachijono; E-mail: agribisnis@gmail.com \\ (Diterima: 22-08-2019; Ditelaah: 23-08-2019; Disetujui: 29-09-2019)
}

\begin{abstract}
Yard land in urban areas has not been utilized for the cultivation of vegetables that are productive and economically profitable. This service program aims to improve the knowledge and skills of PKK members in verticultural and hydroponic vegetable cultivation. Thus, the members can use their yard more productively. The method used in this community service program is training, which consists of counseling as well as demonstrations and practice. Counseling is about the cultivation of vegetable plants vertically and hydroponically has increased the knowledge of participants, from initially not knowing about verticulture to know. The demonstration/practice of growing vegetables the next day made the participants better understand what was delivered in the previous counseling. This encourages the improvement of mothers' skills in growing vegetables vertically and hydroponically. This additional knowledge and skills encourage participants to practice in their own homes.
\end{abstract}

Keywords : Hydropinic, urban farming, verticulture

\section{ABSTRAK}

Lahan pekarangan di perkotaan selama ini belum dimanfaatkan untuk budidaya tanaman sayuran secara produktif dan menguntungkan secara ekonomi. Program pengabdian ini bertujuan untuk meningkatkan pengetahuan dan keterampilan ibu-ibu kader PKK dalam budidaya sayuran secara vertikultur dan hidroponik. Dengan demikian, para ibu tersebut dapat memanfaatkan lahan pekarangannya secara lebih produktif. Metode yang digunakan dalam program pengabdian kepada masyarakat ini adalah pelatihan, yang terdiri dari penyuluhan serta demonstrasi dan praktek. Penyuluhan adalah tentang budidaya tanaman sayuran secara vertikultur dan hidroponik telah meningkatkan pengetahuan peserta, dari yang semula tidak tahu tentang vertikultur menjadi tahu. Demo/praktek budidaya tanaman sayuran yang dilakukan pada keesokan harinya membuat para peserta lebih memahami apa yang disampaikan pada penyuluhan sebelumnya. Hal ini mendorong peningkatan keterampilan ibu-ibu dalam membudidayakan sayuran secara vertikultur dan hidroponik. Tambahan pengetahuan dan keterampilan ini mendorong para peserta untuk mempraktekkannya di rumah masing-masing.

Kata kunci: Hidroponik, urban farming, vertikultur. 
Wachdijono., Wahyuni, S., \& Trisnaningsih, U. (2019). Sosialisasi Urban Farming Melalui Budidaya Tanaman Sayuran Secara Vertikultur dan Hidroponik di Kelurahan Kalijaga, Kecamatan Harjamukti Kota Cirebon. Jurnal Qardhul Hasan; Media Pengabdian kepada Masyarakat, 5(2), 90-94.

\section{PENDAHULUAN}

Pesatnya pembangungan di perkotaan menyebabkan tingginya tingkat alih fungsi lahan dari lahan pertanian ke non-pertanian. Akibatnya sektor pertanian semakin terdesak dan para petani semakin terbatas dalam berusaha tani. Di lain pihak, tingkat perekonomian yang tinggi menyebabkan peningkatan jumlah penduduk yang menyebabkan naiknya permintaan akan bahan pangan. Oleh karenanya, kota dituntut untuk dapat menyediakan bahan pangan yang cukup bagi penduduknya. Urban farming merupakan salah satu alternatif dalam memecahkan masalah pengadaan pangan di perkotaan.

Urban farming merupakan kegiatan pertanian yang dilakukan di kawasan perkotaan dengan memanfaatkan lahanlahan kosong untuk kegiatan pertanian, baik budidaya tanaman maupun peternakan dan perikanan. Keuntungan dari urban farming antara lain tersedianya bahan pangan bagi penduduk kota dan meningkatkan pendapatan petani perkotaan (Huda and Harijati, 2016). Selain itu, urban farming juga mendukung penghijauan kota dan mengatasi krisis lahan pertanian (Suparwoko and Taufani, 2017). Salah satu lahan yang dapat dimanfaatkan untuk kegiatan pertanian adalah lahan pekarangan. Bila dilakukan secara intensif, pengelolaan lahan pekarangan dapat menambah pendapatan penduduk kota (Nurwahyuni 2012). Budidaya tanaman di lahan pekarangan akan teknik budidaya yang dapat digunakan pada lahan sempit antara lain vertikultur dan hidroponik. Vertikultur adalah teknik bercocok tanam secara vertikal atau bertingkat, sesuai diaplikasikan di wilayah perkotaan yang lahan pekarangannya relatif sempit. Strukturnya yang vertikal akan memudahkan membuat dan memeliharanya (Lukman, 2011). Sementara hidroponik adalah bercocok tanam tanpa tanah. Media yang digunakan dapat berupa air atau bahan lain yang bersifat poros (Nurwahyuni, 2012). Selain penggunaan greenhouse, hidroponik merupakan metode yang dapat digunakan untuk mengoptimalkan hasil pada urban farming (Nasihien et al. 2018).

Kelurahan Kalijaga Kecamatan Harjamukti, merupakan pintu gerbang menuju dan ke luar Kota Cirebon dari arah selatan. Penduduknya sangat beragam baik dari status sosial maupun ekonominya. Seperti halya di wilayah perkotaan lain, rata-rata rumah di Kel. Kalijaga mempunyai pekarangan yang relatif sempit. Umumnya mereka memanfaatkan lahan pekarangannya dengan menanam tanaman hias yang bertujuan untuk keindahan saja. Mereka mengetahui bahwa lahan pekarangan dapat ditanami tanaman lain yang dapat dikonsumsi. Namum mereka berpendapat bahwa budidaya tanaman bahan pangan atau obat sulit dilakukan di lahan sempit.

Agar masyarakat Kelurahan Kalijaga dapat memanfaatkan lahan pekarangannya secara lebih produktif, maka Tim Pengabdian kepada Masyarakat Fakultas Pertanian UGJ melakukan pelatihan budidaya tanaman sayuran secara vertikultur dan hidroponik. Tujuannya adalah meningkatkan pengetahuan masyarakat tentang teknik bercocok tanam yang dapat diterapkan di halaman rumah. Selain itu diharapkan pengetahuan ini dapat meningkatkan minat dan keterampilan masyarakat, terutama ibuibu anggota PKK, dalam memanfaatkan lahan pekarangannya secara lebih produktif.

\section{MATERI DAN METODE}

Metode yang digunakan dalam program pengabdian ini adalah pelatihan, yaitu penyuluhan yang disertai demonstrasi atau praktek. Kegiatan dilaksanakan pada tanggal 30 dan 31 Juli 2019. Tempat kegiatan adalah 
di Baperkam RW 12 Kel. Kalijaga. Kelompok sasaran adalah perwakilah PKK dari tiap RW se-Kelurahan Kalijaga beserta anggota masyarakat RW 12 lainnya yang berminat. Penyuluhan dilaksanakan pada tanggal 30 Juli 2019, dengan materi Budidaya Tanaman Secara Vertikultur dan Hidroponik. Materi disampaikan oleh Siti Wahyuni, dosen Program Studi Agroteknologi UGJ dan diikuti oleh sekitar 28 orang peserta. RW 12 dipilih sebagai lokasi pelatihan karena masyarakat RW 12 sudah terbiasa bercocok tanam di lahan pekarangan namun masih sebatas tanaman hias dan budidayanya secara konvensional. Pada saat rapat koordinasi, perwakilan dari RW 12 mengajukan diri untuk menjadi lokasi pelatihan Budidaya Tanaman Secara Vertikultur dan Hidroponik, karena keinginan mereka untuk memanfaatkan pekarangan secara lebih produktif.

Demo budidaya tanaman sayuran dilaksanakan pada tanggal 31 Juli 2019. Wadah yang digunakan untuk vertikultur adalah pipa paralon yang telah diberi lubang tanam di sekelilingnya (Gambar 1a). Media tanam yang digunakan adalah campuran antara tanah, pupuk kandang, dan arang sekam dengan perbandingan 1:1:1. Paralon diisi campuran media tanam sampai penuh, kemudian pada setiap lubang tanam ditanam benih kangkung, selada, dan caisim. Peserta dibagi ke dalam tiga kelompok dan setiap kelompok menanam satu jenis sayuran pada dua paralon. Sebelum ditanam, benih direndam terlebih dahulu dalam air. Benih yang mengambang di permukaan air dibuang, dan yang digunakan adalah benih yang tenggelam. Setelah ditanami benih, paralon kemudian disiram dan disimpan di tempat yang teduh. Bila tanaman telah tumbuh baru dipindahkan ke tempat yang terpapar sinar matahari.

Untuk hidroponik, instalasi yang digunakan terdiri dari kerangka besi, tempat penanaman dari paralon yang diberi lubang tempat pot, dan menggunakan generator mini untuk sirkulasi air (Gambar 1b). Nutrisi yang digunakan adalah $\mathrm{AB}$ Mix, yang dilarutkan ke dalam air, yang kemudian dialirkan ke paralon pada instalasi hidroponik. Sebagai tempat kedudukan tanaman digunakan rockwoll yang disimpan dalam pot yang nantinya akan ditempatkan pada instalasi hidroponik. Benih yang digunakan pada hidroponik adalah selada. Untuk mengetahui apakah penyuluhan meningkatkan pengetahuan peserta atau tidak, dilakukan survei kepada peserta baik sebelum dan sesudah penyuluhan. Selain itu dilakukan monitoring dan evaluasi selama satu bulan setelah praktek budidaya sayuran secara vertikultur dan hidroponik.

Gambar 1. Peralatan/ Wadah yang digunakan untuk vertikultur (a) dan Hidroponik (b).

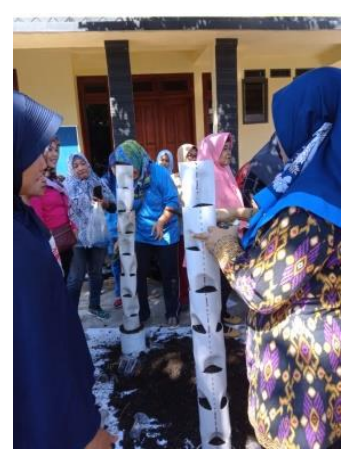

(a)

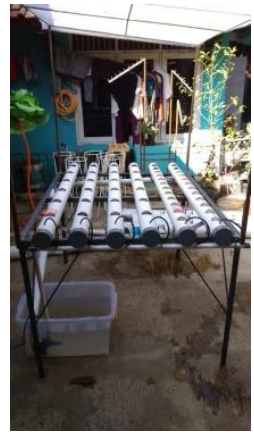

(b)

\section{HASIL DAN PEMBAHASAN}

Berdasarkan hasil wawancara sebelum penyuluhan, sebagian besar peserta pelatihan belum pernah mendengar tentang vertikultur sementara sebagian ada yang sudah mendengar tentang hidroponik tetapi tidak tahu bagaimana caranya. Dalam materi penyuluhan disampaikan apa yang dimaksud dengan vertikultur beberapa teknik yang dapat digunakan dalam budidaya tanaman sayuran di lahan pekarangan. Wadah yang akan digunakan dalam vertikultur bisa bermacam-macam, baik model, ukuran maupun jenis bahannya. Namun yang penting, wadah tersebut harus mudah dibuat dan dipelihara oleh penggunanya (Lukman 2011).

Dalam penyuluhan juga dijelaskan tentang pengertian hidroponik dan teknik-teknik hidroponik yang dapat digunakan untuk skala rumah tangga. Wadah yang digunakan pada 
kegiatan di RW 12 adalah pipa paralon yang diberi lubang tanam di beberapa bagian. Agar dapat berdiri tegak, pada bagian bawahnya ditanam dalam ember yang diberi adukan semen. Wadah dari paralon ini memenuhi syarat wadah vertikultur, yaitu kaut dan mudah dipindah-pindahkan (Ningsih, Rasyid, and Muhidin 2016). Tanaman yang ditanam dalam wadah vertikultur sebaiknya berumur pendek atau tanaman semusim serta bernilai ekonomi tinggi (Ariati 2017). Oleh karena itu, yang digunakan adalah kangkung dan selada. Peserta dibagi ke dalam tiga kelompok, masing-masing menanam satu jenis tanaman sayuran dalam dua paralon (Gambar 2). Dengan demikian ada enam paralon yang sudah ditanami. Setelah disiram, paralon kemudian disimpan di tempat yang teduh sampai dengan benih berkecambah.

Gambar 2. Peserta Pelatihan sedang Praktek budidaya sayuran secara vertikultur dan hidroponik.

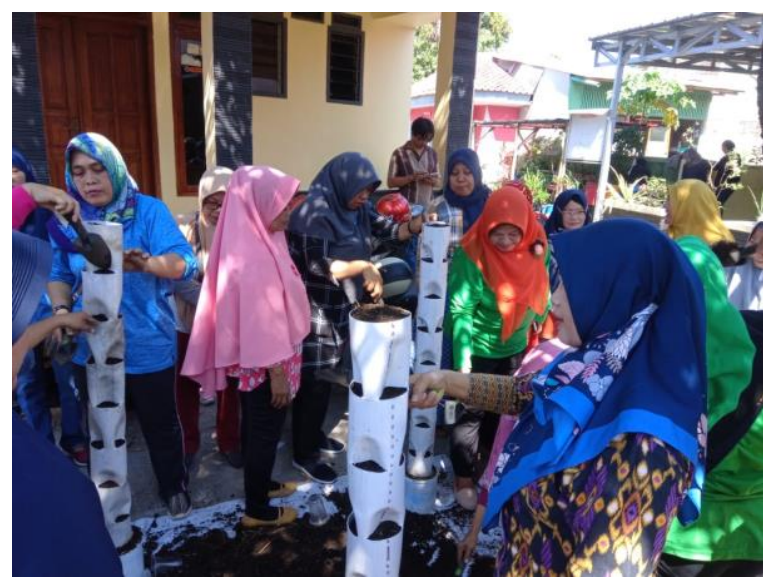

Pada demo budidaya sayuran secara hidroponik, peserta masih merasa ragu apakah dapat menerapkannya dalam skala rumah tangga. Hal ini disebabkan karena teknik yang didemonstrasikan menggunakan instalasi yang relatif tidak sederhana (Gambar 2). Namun demikian, peserta antusias dalam mempelajari cara kerja instalasi hidroponik yang disediakan. Mereka berharap ada pendampingan untuk budidaya tanaman sayuran secara hidroponik dan demo/praktek hidroponik untuk teknik yang lebih sederhana.

Evaluasi dan monitoring yang dilakukan seminggu setelah praktek menunjukan bahwa benih yang dikecambahkan pada pot paralon telah tumbuh tetapi yang dikecambahkan pada rockwoll (untuk hidroponik) belum tumbuh dengan sempurna sehingga belum bisa dipindahkan ke instalasi hidroponik. Pertumbuhan bibit yang kurang baik diduga karena persemaikan dilakukan di ruang tertutup sehingga kekurangan sinar matahari.

\section{KESIMPULAN}

Masyarakat di RW 12 Kelurahan Kalijaga, Kecamatan Harjamukti, Kota Cirebon belum memanfaatkan lahan pekarangan dengan budidaya tanaman sayuran. Hal ini disebabkan karena mereka berpendapat, tanaman sayuran tidak menguntungkan jika dibudidayakan di lahan sempit. Pelatihan budidaya tanaman sayuran telah meningkatkan pengetahuan dan keterampilan para anggota PKK dan masyarakat lain yang mengikutinya. Hal ini mendorong para ibu untuk mencoba mempraktekannya di rumah masing-masing. Denga demikian mewujudkan pertanian di perkotaan atau urban farming.

\section{UCAPAN TERIMA KASIH}

Ucapan terima kasih disampaikan kepada Kementrian Riset, Teknologi, dan Pendidikan Tinggi RI yang telah membiayai kegiatan ini melalui hibah untuk kategori Pengabdian Kepada Masyarakat Kompetitif Nasional untuk skema Program Kemitraan Masyarakat Stimulus (PKMS) tahun 2019.

\section{DAFTAR PUSTAKA}

Ariati, Putu Eka Pasmidi. 2017. "Produksi Beberapa Tanaman Sayuran Dengan Sistem Vertikultur Di Lahan Pekarangan." Agrimeta 7 (19): 76-86.

Huda, Nurul, and Sri Harijati. 2016. "Peran Penyuluh Dalam Pemberdayaan Masyarakat Pertanian Perkotaan." Repository.Ut.Ac.Id, 205-22. https://scholar.google.co.id/scholar?h $\mathrm{l}=\mathrm{id} \&$ as_sdt=0\%2C5\&q=Peran+Penyul 
uh+dalam+Pemberdayaan+Masyaraka $\mathrm{t}+$ Pertanian+Perkotaan\&btnG $=$.

Lukman, Liferdi. 2011. "Teknologi Budidaya Tanaman Sayuran Secara Vertikultur." Academia.Edu, no. c: 2-6. https://s3.amazonaws.com/academia. edu.documents/34781420/verikultur. pdf?response-contentdisposition=inline\%3B

filename\%3DTeknologi_Budidaya_Tan aman_Sayuran_Secar.pdf\&X-Amz-

Algorithm=AWS4-HMAC-SHA256\&X-

Amz-

Credential=AKIAIWOWYYGZ2Y53UL3 A\%2F20190815\%2Fus-e.

Nasihien, Ronny Durrotun, Diah Ayu Restuti Wulandari, Achfas Zacoeb, . Harimurti, and M. Ikhsan Setiawan. 2018. "Teknologi Portable Inflated Greenhouse Sebagai Fasilitas Pendukung Peningkatan Ketahanan Pangan Dan Pertanian Perkotaan (Urban Farming)." Jurnal Darussalam: Jurnal Pendidikan, Komunikasi Dan Pemikiran Hukum Islam 9 (1): 153. https://doi.org/10.30739/darussalam .v9i1.123.

Ningsih, Gumoyo Mumpuni, Harun Rasyid, and Muhidin. 2016. "Budidaya Sayuran Secara Vertikultur." In Seminar Nasional Dan Gelar Produk 2016, 33439. Malang: UMM. http://lampung.litbang.pertanian.go.id /ind/index.php/berita/4-infoaktual/760-budidaya-sayuran-secaravertikultur.

Nurwahyuni, Endah. 2012. "OPTIMALISASI PEKARANGAN MELALUI BUDIDAYA TANAMAN SECARA HIDROPONIK." In Prosiding Seminar Nasional Optimalisasi Pekarangan, Semarang 6 November 2012, 863-68. Semarang: UNDIP Press.

Suparwoko, and Betri Taufani. 2017. "Urban Farming Construction Model on the Vertical Building Envelope to Support the Green Buildings Development in Sleman, Indonesia." Procedia Engineering 171: 258-64. https://doi.org/10.1016/j.proeng.201 7.01.333. 